\title{
Hayat Dişı Sigortacılık ve Ekonomik Büyüme İlişkisi: 1985-2018 Türkiye Örneği
}

\author{
Serdar BUDAK ${ }^{1}$ ve Aylin MERCAN ALKAN ${ }^{2}$
}

$\ddot{O} z$

Sigortacılık, risklerle dolu evrende, insanların kendilerini bu risklerin doğuracağı kayıplara karşı güvence altına alma ihtiyacından doğmuş ve günümüzde önemli bir finansal sektör haline gelmiştir. Sigorta yalnızca prim ve tazminat ilişkisinden ibaret olmayan, ekonomik ve toplumsal çok yönlü işlevleri olan bir yapıdır. Sigorta etkin bir risk yönetimi ile ekonomik kayıpları azaltabilmekte ve havuzda biriken fonlarla yatırımları destekleyebilmektedir. Bu çalışmada da sigortacıllğın ekonomik işlevlerinden yola çıkılarak hayat dışı sigortaların ekonomik büyüme ile ilişkisini analiz etmek amaçlanmıştır. Yöntem olarak öncelikle değişkenlerde birim kök varlı̆̆1 Augmented Dickey-Fuller (ADF) ve PhillipsPerron (1988) birim kök testleri ile incelenmiştir. Ardından değişkenler arasında uzun dönemli ilişki olup olmadığını belirlemek amacıyla (Banerjee vd. 2017) tarafından geliştirilen Fourier ADL eşbütünleşme testi uygulanmıştır. Son olarak eşbütünleşik değişkenlerin uzun dönem parametre katsayıları belirlemek amacıyla dinamik en küçük kareler (DOLS) yöntemi kullanılmıştır. Sonuç olarak hayat dışı sigortacılığın ekonomik büyümeyi pozitif yönde etkilediği tespit edilmiştir.

Anabtar Kelimeler: Sigorta, Hayat Dış1 Sigorta, Ekonomik Büyüme, Fourier ADL

The Relationship between Non-Life Insurance and Economic Growth: 1985-2018 Evidence from Turkey

\begin{abstract}
Insurance has emerged from the need of people to secure themselves against the losses caused by these risks in a universe full of risks and it has become an important financial sector today. Insurance is not only a premium and indemnity relationship, but also a structure that has multifaceted economic and social functions. Insurance can reduce economic losses with an effective risk management and support investments with the funds accumulated in the pool. This study, based on the economic functions of insurance, is aimed to analyze the relationship between non-life insurance and economic growth. As a method, the presence of unit root in variables was examined using Augmented Dickey-Fuller (ADF) and Phillips-Perron (1988) unit root tests. Then, the Fourier ADL cointegration test developed by (Banerjee et al., 2017) was applied to determine whether there was a long-term relationship between variables. Finally, the dynamic least squares (DOLS) method was used to determine the long-term parameter coefficients of the cointegrated variables. As a result, it has been determined that non-life insurance has a positive effect on economic growth.
\end{abstract}

Key Words: Insurance, Non-Life Insurance, Economic Growth, Fourier ADL

\section{Atıf İçin / Please Cite As:}

Budak, S. ve Mercan Alkan, A. (2022). Hayat dış1 sigortacılık ve ekonomik büyüme ilişkisi: 1985-2018 Türkiye örneği. Manas Sosyal Araștirmalar Dergisi, 11(1), 218-229.

\footnotetext{
${ }^{1}$ Dr. Öğr. Üyesi - Tokat Gaziosmanpaşa Üniversitesi Turhal Uygulamalı Bilimler Fakültesi, serdar.budak@gop.edu.tr D ORCID: 0000-0002-0338-5490

2 Arş. Gör. - Tokat Gaziosmanpaşa Üniversitesi Turhal Uygulamalı Bilimler Fakültesi, aylin.mercan@gop.edu.tr

(iD ORCID: 0000-0001-7611-8724
} 


\section{Giriş}

Sigorta, bireylerin olası riskler karşısında gerçekleşebilecek kayıplara karşı kendilerini güvence altına alma ihtiyacından doğmuş ve günümüzde önemli bir finansal sektör konumuna gelmiştir. Sigorta sektörü ekonomi içerisinde taşıdığı öneme rağmen Türkiye'de gerekli seviyelere ulaşamamış, gelişmiş ülkelerin aksine bankaların oldukça gerisinde kalmıştır. Oysaki sigorta fon yaratma kapasitesine sahip olduğundan yatırımları finanse ederek ekonomik kalkınmayı destekleyen çok yönlü işlevleri bulunan bir finansal hizmet konumundadır. Sigortanın sunduğu potansiyeller karşısında yüksek enflasyon, kişi başına düşen gelirin azlı̆̆1, korunma kültürünün topluma yerleşmemiş olması, geleneksel bakış açısı (kayıpları akraba veya komşudan gelecek borçlarla telafi etme) gibi faktörler gelişimini engellemektedir.

Gelişmiş ülkelerin finansal yapılarına bakıldığında oldukça etkin ve gelişmiş bir sigortacılık altyapısına sahip oldukları görülmektedir. Çünkü sigortacıllğın riskli zamanlarda kayıpları azaltarak veya telafi ederek toplumsal refahın artmasını sağlayan birçok işlevi bulunmaktadır. Sigorta yatırımları teşvik ederek ve yeni iş alanları yaratarak ülke ekonomisine katkıda bulunmaktadır. Sigorta yalnızca bireylerin değil ülkenin varlıklarını da olası kayıplara karşı teminat altına almaktadır. Uluslararası düzeyde ekonomik ilişkilerin gelişmesini ve sosyo-ekonomik kayıpların minimuma indirilmesini sağlamaktadır. Tüm bu etkileri göz önünde bulundurulduğunda sigortacılığın ekonomik büyüme ile yakın iliş̧ki içerisinde olduğu görülebilmektedir. Nitekim gelişmiş ülkelerin kişi başına düşen prim ve yurtiçi hassıla oranları da bu durumu destekleyici nitelik taşımaktadır.

Sigortanın makroekonomik açıdan önemli işlevlerinden biri de yurtiçi tasarrufları pozitif yönde etkilemesidir. Burada yapılan sözleşmeler ile belirlenen primler hem riskleri azalmasına sağlar hem de tasarrufların önemli bir kaynağıdır. Yurtiçi tasarrufların yatırıma dönüşmesi dolayısıyla ekonomik büyümeyi desteklemesi literatürde büyüme modellerine konu olmuştur. Yurtiçi tasarruflar ve ekonomik büyüme ilişsisinin teorik çerçevesi Harrod (1939) ve Domar (1946) büyüme modellerinde görülmektedir. Modelde ekonomik büyüme hızı marjinal tasarruf oranı (s) ve sermaye hasıla oranı (v) olmak üzere iki kavrama bağlanmaktadır. Burada marjinal tasarruf oranı ile büyüme hızı arasında pozitif bir ilişki bulunmaktadır. Büyüme modellerinden bir diğer yaklaşım olan Solow'un (1956) modeli sermayenin marjinal verimliliğindeki azalma nedeniyle büyümenin sonuç olarak sonlanacağını ileri sürmektedir.

Hayat dış1 sigortalar özelinde değerlendirildiğinde, sektörün ekonomik büyüme ile ilişkisini inceleyen kısıtlı sayıda çalışma bulunmaktadır. Çalışmada yalnızca uzun vadeli hayat ürünlerinin değil aynı zamanda hayat dışı ürünlerin de ekonomiye nasıl bir etkisi olduğu konusunda değerlendirmeler yaparak literatüre katkıda bulunmak amaçlanmıştır. Çalışmanın önemi tüm finansal hizmet sektörü içerisinde değeri yeterince anlaşılamamış olan sigortacılık sektörüne ilişkin algının ekonomik perspektiften aktarılmaya çalışılmasıdır. Sigorta sektörünün ekonomi üzerindeki işlevleri ortaya koyularak, yapilan analizlerle bu yorumların somutlaştırılması amaçlanmıştır. Türkiye'de hayat dışı sigorta sektörünün payı ve ürünlerin yapısı düşünüldüğünde, ekonomik büyüme ile ilişkinin incelenmesi ayrıca bir önem taşımaktadır. Toplumun sigorta bilincinin yerleşmesi ve sigorta kültürünün oluşması açısından sigortacıllğın ekonomik ve toplumsal faydalarını sunabilecek çalışmaların çoğalması ve aktarılması faydalı olabilecektir. Bu çalışmada da finansal hizmetler sektörü arasında sigortacıllğın önemi belirtilerek hayat dışı sigortalar ve ekonomik büyüme arasındaki ilişki analiz edilecektir.

\section{Sigortacılığa Genel Bakış}

İnsanlar tarih boyunca ürettiği değeri ve kazancı olası kayıplardan korumak için birçok yöntem geliştirmiş ve kullanmıştır. Bu yöntemler içinde yıllar boyunca gelişerek günümüzdeki modern halini almış olan sistemlerden birisi de sigortacillk olmuştur. Sigorta, riski paylaşma prensibi ile hareket eden, kişileri karşılaşabilecekleri zararlara karşı teminat altına alan bir güvence sistemidir. (Uralcan, 2014) Sigortacılık branşları konusuna göre değerlendirildiğinde hayat sigortaları ve hayat dışı sigortalar olmak üzere iki grupta incelenmektedir. Hayat dışı sigorta branşında; kaza, yangın, deprem, nakliyat, mühendislik, sorumluluk, tarım, genel zararlar ve finansal kayıp sigortaları yer almaktadır (Türkiye Sigorta Birliği [TSB], 2019).

Sigorta yalnızca prim karşılığında alınan bir poliçe olarak görülmemeli, aynı zamanda ekonomik ve toplumsal işlevleri olan bir yapı olarak değerlendirilmelidir. Gelişmekte olan ülkelerde kredibiliteyi artırarak girişimcileri cesaretlendirmekte ve girişimci sayısını artırabilmektedir. Sigorta ekonominin ihtiyaç duyduğu sermaye birikimini sağlayan bir tasarruf yöntemidir. Nakliyat, emtea gibi sigorta ürünleriyle sunduğu güvenceler sayesinde uluslararası ticareti teşvik ederek ekonominin canlanmasını sağlamaktadır. Aynı 
zamanda sunduğu istihdam firsatlarıyla işsizlik oranının azalmasını ve toplumsal refahın artmasını sağlamaktadır (Uralcan, 2012, s. 128). Rakamlara bakıldığında 2019 yılında toplam 19.062 kişi sigorta, reasürans ve emeklilik şirketlerinde istihdam edilmektedir. Acente, eksper, bireysel emeklilik aracısı gibi diğer sektör çalışanları da eklendiğinde sigorta sektörü toplamda 200 bini aşkın kişiye istihdam sağlamaktadır (Türkiye Sigorta Birliği [TSB], 2019).

Hayat dışı sigorta ürünlerinin yaygınlaşması ve sigortalı kişi sayısının çoğalması finansal kayıpları en aza indirerek ülke ekonomisi üzerinde oluşabilecek yükü hafifletmektedir. Deprem, sel, tsunami gibi doğal afetler sonucu ortaya çıkan aşırı hasarlar gelişmiş bir sigortacılık sistemi ile ülke ekonomisine en az kayıp verecek şekilde atlatılabilmektedir. Sigortadaki fonlar ülkelerin en kısa sürede afet öncesi düzene dönebilmesini sağlayarak ekonominin aşırı olaylara karşı esnekliğini artırabilmektedir. Bu nedenle deprem, yangın gibi hayat dışı sigorta branşlarının toplum içerisinde yaygınlığının yani sigortalılık oranlarının artması önem taşımaktadır. Sigorta yalnızca risk gerçekleştikten sonra yapılan tazminat ödemesi olmasının ötesinde bir risk yönetim sürecini kapsamaktadır. Son dönemde iklim değişikliği, kuraklık, salgın hastalıklar ve doğal afet risklerinden doğan kayıpların giderek artması sigortacilığın ülkeler bazında daha fazla konuşulmasına neden olmaktadır.

\section{Türkiye'de Sigortacılık Sektörü}

258 Milyar TL (31.09.2020) aktif büyüklüğü ile Türk sigorta sektörü büyüme açısından önemli bir potansiyele sahiptir. Türkiye'nin genç ve dinamik yapısı ve devletin tarım ve DASK gibi ürünlerde sektöre stratejik desteği sigortacılık özelinde çeşitli firsatları doğurabilecektir. Aynı zamanda Türkiye ekonomisin uzun vadede sahip olduğu yüksek büyüme potansiyeli ve düşük penetrasyon oranları da sigortacılık için büyüme beklentilerini destekleyebilecektir. 2020 yılında sektör Covid-19 küresel salgınıyla karşı karşıya kalmış ve bu küresel risk ile mücadele etmiştir. Sigorta sektörünün pandemiye rağmen 2020 y1lında da büyüme kaydettiği görülmektedir (Türkiye Sigorta Birliği [TSB], 2020).

Tablo 1. Türk Finans Sektörü Bilanço Büyüklükleri

\begin{tabular}{|c|c|c|c|c|c|}
\hline Bankalar & $1.994,24$ & $2.357,00$ & $2.595,40$ & $3.257,84$ & $4.490,80$ \\
\hline \multirow{2}{*}{$\begin{array}{l}\text { Sigorta, Reas. Emek. Şirketleri } \\
\text { Emeklilik yatırım fonları }\end{array}$} & 81,02 & 98,4 & 122,2 & 152,3 & 178,4 \\
\hline & 37,76 & 48 & 60,8 & 77,7 & 88,4 \\
\hline Menkul Kıymet Yatırım Fonları & 33,3 & 37,2 & 41,8 & 54,2 & 46,8 \\
\hline Finansal Kiralama Şirketleri & 32,6 & 40,6 & 48,5 & 58,1 & 68,5 \\
\hline Faktöring Şirketleri & 26,5 & 26,7 & 33,1 & 43,7 & 34,6 \\
\hline Tüketici Finansman Şirketleri & 20,3 & 27,2 & 32,8 & 39,1 & 39,7 \\
\hline Arac1 Kurumlar & 15,1 & 15,3 & 21,2 & 23,1 & 21,9 \\
\hline Gayrimenkul Yatırım Ort. & 22 & 21,3 & 25 & 26,9 & 19,4 \\
\hline Girişim Sermayesi Yatırım Ort. & 1,5 & 1,3 & 1,1 & 2,6 & 1,5 \\
\hline Genel Toplam & $2.226,56$ & $2.625,05$ & $2.921,00$ & $3.657,90$ & $4.277,80$ \\
\hline
\end{tabular}

Kaynak: Hazine ve Maliye Bakanlığı. (2018). Sigorta Denetleme Kurulu, Sigortacılık ve Bireysel Emeklilik Faaliyetleri Hakeknda Rapor, s.3.

Toplum refahının yükselmesi, sosyo-ekonomik gelişimin sağlanması, ekonomik kalkınmaya katkıda bulunması gibi faydaları olan sigortacılık sisteminin Türkiye'de diğer finansal hizmet sektörü olan bankacilığa göre oldukça küçük bir paya sahip olduğu söylenebilmektedir. Tablo 1'de verilen 2018 y1lı verilerine göre tüm finans sektörü içerisinde bankalar bilanço büyüklüğü \%90,4 ile ilk siradayken sigortacılık \%4,17 ile ikinci sırada gelmektedir. Son beş y1l içerisinde hala düşük bir paya sahip olmakla birlikte, büyüme potansiyeli bakımından bir avantaj olarak da değerlendirilebilmektedir. Nitekim sigorta şirketleri arasında yabancı sermayenin yüksekliği ve gerçekleşen satın alma ve birleşmeler bu durumun bir kanıtı olarak gösterilebilmektedir. Nitekim sigorta şirketleri arasında yabancı sermayenin yüksekliği ve gerçekleşen satın alma ve birleşmeler bu durumun bir kanıtı olarak gösterilebilmektedir. 2019 yılında 63 sigorta şirketi içerisinde 41 şirket uluslararası ortaklı olarak faaliyet göstermektedir. 2019 sonu itibariyle faaliyette bulunan 38 adet hayat dışı sigorta şirketleri arasında 23'ü yabancı sermayelidir. Yine 63 sigorta şirketi arasında yabancı sermaye payının \%50'den fazla olduğu 37 şirket bulunmaktadır (Hazine ve Maliye Bakanlığ1 [HMB], 2018). 
Tablo 2. Prim Üretimi ve Teminat Tutarlar

\begin{tabular}{|c|c|c|c|c|c|}
\hline \multicolumn{6}{|l|}{ Prim Üretimi } \\
\hline Hayat Dı̧̧ı Prim Üretimi & 22,711 & 27,296 & 35,450 & 39,712 & 47,669 \\
\hline Hayat Prim Üretimi & 3,280 & 3,761 & 5,039 & 6,844 & 6,920 \\
\hline Toplam Prim & 25,991 & 31,056 & 40,488 & 46,556 & 54,589 \\
\hline Hayat Dı̧̧ı Payı & 87,38 & 87,89 & 87,55 & 85,30 & 87,32 \\
\hline Hayat Payı & 12,62 & 12,11 & 12,45 & 14,70 & 12,68 \\
\hline \multicolumn{6}{|l|}{ Teminat Tutarı } \\
\hline Hayat Dı̧̧ı Teminat & 75.961 .929 & 85.389 .071 & 89.115 .156 & 106.268 .467 & 125.886 .885 \\
\hline Hayat Teminatı & 564,914 & 670,804 & 746,487 & 918,264 & 1.005 .270 \\
\hline Toplam Teminat & 76.526 .843 & 86.059 .874 & 89.861 .644 & 107.186.731 & 126.892 .104 \\
\hline
\end{tabular}

Kaynak: T.C. Hazine ve Maliye Bakanlığı. (2018), Sigorta Denetleme Kurulu, Sigortacullk ve Bireysel Emeklilik Faaliyetleri Hakkemda Rapor, s.4.

Tablo 2'de 2018 yll sonu itibariyle toplam prim üretimi 54,589 milyar TL olan sigortacillk sektöründe hayat dışı primlerinin payının \%87 olması dikkat çekmektedir. Son beş yıla bakıldığında hayat dışı branşlar hayat branşına göre \% $\% 5$ 'in üzerinde pay alarak istikrarını sürdürmüştür. Hayat dışı toplam prim üretimi ise 2017 yllına göre \%20,2 artarak 47,669 milyar TL olarak gerçekleşmiştir.

Gelişmiş ülkeler ile kıyaslandığında Türkiye'de sigortacılığın istenilen seviyede olmadığını söyleyebilmek mümkündür. Reel büyüme oranları gelişmiş piyasalarda hayat dişı sigortalar için $\% 1,9$ olarak gerçekleşirken Türkiye'de bu oran \%0,5 olmuştur. Kişi başına düşen prim tutarlarına bakıldığında 2019 yılında Dünya ortalaması 818 ABD Doları iken Türkiye'de 111 ABD Doları hayat dışı ürünlerde olmak üzere 131 ABD Doları olmuştur. Direkt primlerin GSYH içindeki payları incelendiğinde Türkiye'de 1,45 puan gerçekleşirken dünyada 7,23 seviyesindedir. Bu oranlara bakıldığında Türkiye’nin sigortacıllk sektöründe gelişme sağlayabilmesi için önündeki engeller değerlendirilmeli ve etkili çözümler üretilmelidir. Sigortanın sunduğu teminatların lüks bir finansal ürün olarak algılanması ve faydalarının yeterli düzeyde bilinmemesi taleplerin azalmasına neden olabilmektedir. Buna karşın belirsizlik dönemlerinde gerek bireylerin gerekse işletmelerin risklere karşı savunmasız kalmaması ve zararı en aza indirerek atlatması sigorta ile sağlanabildiğinden bu konuda sigorta bilincinin ve kültürünün oluşturulması faydalı olabilecektir (Sigma, 2020).

\section{Literatür}

Türkiye'de sigortacılık ve ekonomik büyüme arasındaki ilişkiyi inceleyen kısıtlı sayıda çalışma bulunmaktadır. Hayat dışı sigorta branşları özelinde ise bu çalışma ilk olma özelliği taşımaktadır. Aşağıdaki tabloda yerli ve yabancı literatürden çeşitli çalışmalar sıralanmıştır: 
BUDAK ve MERCAN ALKAN

Hayat Dışı Sigortacılık ve Ekonomik Büyüme İlişkisi: 1985-2018 Türkiye Örneği

Tablo 3. Yerli ve Yabancı Literatürden Cesitti Calışmalar

\begin{tabular}{|c|c|c|c|}
\hline $\begin{array}{l}\text { Z. Şenol vd. } \\
(2020)\end{array}$ & 36 Ülke & Panel Nedensellik & $\begin{array}{l}\text { 1985-2018 yılları arasında yapılan analizlere göre hayat ve } \\
\text { hayat dışı sigorta sektörü ile ekonomik büyüme arasında } \\
\text { nedensellik ilişkisi bulunmaktadır. Sigortacılık ekonomik } \\
\text { büyümeye katkı sağlamaktadır. }\end{array}$ \\
\hline $\begin{array}{l}\text { N. Kaya ve } \\
\text { N.Ö. Beşer } \\
\quad(2020)\end{array}$ & $\begin{array}{c}\text { AB (Avrupa Birliği) } \\
\text { Ülkeleri }\end{array}$ & Panel Veri Analizi & $\begin{array}{l}\text { Ekonomik büyüme ve sigorta prim hacimleri arasında } \\
\text { uzun dönemli eş bütünleşme ilişkisi bulunmaktadır. } \\
\text { Sigorta hacminden ekonomik büyümeye doğru tek yönlü } \\
\text { nedensellik saptanmıştır. }\end{array}$ \\
\hline $\begin{array}{l}\text { N. Apergis ve } \\
\text { T. Poufinas } \\
\quad \text { (2020) }\end{array}$ & $\begin{array}{l}\text { OECD (Ekonomik } \\
\text { İşbirliği ve Kalkınma } \\
\text { Örgütü) Ülkeleri }\end{array}$ & Panel Veri Analizi & $\begin{array}{l}\text { 2006-2016 yılları arasında } 27 \text { ülkenin incelendiği } \\
\text { çalışmaya göre sigorta penetrasyonu ve prim üretimi ile } \\
\text { ekonomik büyüme arasında olumlu yönde ilişki } \\
\text { bulunmaktadır. }\end{array}$ \\
\hline $\begin{array}{l}\text { F. Şamiloğlu } \\
\text { vd. (2019) }\end{array}$ & Türkiye & $\begin{array}{c}\text { Johansen Eşbütünleşme } \\
\text { Testi }\end{array}$ & $\begin{array}{l}2004-2018 \text { yılları arasında yapılan analizlere göre artan } \\
\text { istihdamın sigorta sektörü üzerinde olumlu bir etkisi } \\
\text { bulunmaktadır. }\end{array}$ \\
\hline $\begin{array}{l}\text { E. Yenisu } \\
\text { (2019) }\end{array}$ & Türkiye & $\begin{array}{l}\text { ARDL (Gecikmesi } \\
\text { Dağıtılmıs Otoregresif. } \\
\text { Model) Sinır Testi, Hata } \\
\text { Düzeltme Modeli }\end{array}$ & $\begin{array}{l}2010-2018 \text { yılları arasında yapılan analizlere göre } \\
\text { sigortacılık ile ekonomik büyüme arasında kısa ve uzun } \\
\text { vadede anlamlı bir ilişki bulunmaktadır. }\end{array}$ \\
\hline $\begin{array}{l}\text { Ş. D. Demirci } \\
\text { ve F. Zeren } \\
(2017)\end{array}$ & 13 OECD Ülkesi & $\begin{array}{l}\text { Panel Birim Kök Test, } \\
\text { Panel Nedensellik Testi }\end{array}$ & $\begin{array}{l}\text { 1983-2011 y1lları arasında yapılan analizlere göre ile } \\
\text { ekonomik büyüme sigortacılık arasında olumlu bir ilişki } \\
\text { bulunmaktadır. }\end{array}$ \\
\hline $\begin{array}{l}\text { R. P. Pradhan } \\
\text { vd. (2017) }\end{array}$ & 19 AB Ülkesi & $\begin{array}{c}\text { Granger Nedensellik } \\
\text { Testi }\end{array}$ & $\begin{array}{l}\text { 1980-2014 y1lları veri analizlerine göre hayat, hayat dışı ve } \\
\text { toplam sigorta yoğunluğu ile ekonomik büyüme arasında } \\
\text { hem tek yönlü hem de çift yönlü ilişki bulunmaktadır. }\end{array}$ \\
\hline $\begin{array}{l}\text { G. C. Liu vd. } \\
\text { (2016) }\end{array}$ & G-7 Ülkeleri & $\begin{array}{l}\text { Bootstrap Granger } \\
\text { Nedensellik Testi }\end{array}$ & $\begin{array}{l}\text { 1980-2011 y1llarının incelendiği çalışmaya göre uzun } \\
\text { vadede ekonomik büyümeyi sürdürebilmek ve risk } \\
\text { yönetimini geliştirebilmek için sigorta sektörüne } \\
\text { yatırımlar yapılması gerekmektedir. }\end{array}$ \\
\hline $\begin{array}{l}\text { A. Köse vd. } \\
\text { (2009) }\end{array}$ & Türkiye & $\begin{array}{c}\text { Johansen Eşbütünleşme } \\
\text { Testi }\end{array}$ & $\begin{array}{l}\text { 1981-2008 dönemleri içerisinde yapılan analizlere göre } \\
\text { gayri safi yurt içi hasıladan direk prim üretimlerine doğru } \\
\text { tek yönlü bir nedensellik ilişkisi bulunmaktadır. }\end{array}$ \\
\hline $\begin{array}{l}\text { P. Haiss ve K. } \\
\text { Sümegi (2008) }\end{array}$ & 25 Avrupa Ülkesi & Panel Veri Analizi & $\begin{array}{l}\text { 1992-2005 yılları arasında yapılan analizlere göre hayat } \\
\text { sigortası ve sorumluluk sigortaları ile ekonomik büyüme } \\
\text { arasında olumlu bir ilişki bulunmaktadır. }\end{array}$ \\
\hline $\begin{array}{l}\text { K.C. } \\
\text { Vadlamannati } \\
\text { (2008) }\end{array}$ & Hindistan & $\begin{array}{l}\text { Birim Kök Testi, } \\
\text { Granger Nedensellik } \\
\text { Testi }\end{array}$ & $\begin{array}{l}\text { 1980-2006 yılları arasında yapılan analizlere göre sigorta } \\
\text { sektöründe yapılan reformlar ile ekonomik büyüme } \\
\text { arasında eş bütünleşme ilişkisi bulunmaktadır. }\end{array}$ \\
\hline $\begin{array}{l}\text { M. Kugler ve } \\
\text { R. Ofoghi } \\
\text { (2005) }\end{array}$ & Birleşik Krallık & $\begin{array}{c}\text { Johansen Eşbütünleşme } \\
\text { Testi }\end{array}$ & $\begin{array}{l}\text { Yapılan analizlere göre uzun vadede sigorta sektörü ile } \\
\text { ekonomik büyüme arasında anlamlı bir ilişki } \\
\text { bulunmaktadır. }\end{array}$ \\
\hline $\begin{array}{l}\text { D. Ward ve R. } \\
\text { Zurbruegg } \\
(2000)\end{array}$ & 9 OECD Ülkesi & $\begin{array}{c}\text { Granger Nedensellik } \\
\text { Testi }\end{array}$ & $\begin{array}{l}\text { 1961-1996 dönemi için yapılan analizlere göre sigorta } \\
\text { sektörünün ekonomik büyümeye olan etkisi her ülke } \\
\text { özelinde kendi koşullarına göre değerlendirilmeli ve } \\
\text { çalışılmalıdır. Bazı ülkelerde sigorta endüstrisi ekonomik } \\
\text { büyümeyi etkilerken bazılarında tersi geçerli olmuştur. }\end{array}$ \\
\hline
\end{tabular}

\section{Yöntem}

Çalışmanın bu kısmında değișkenlerde birim kök varlığı Augmented Dickey-Fuller (ADF) ve PhillipsPerron (1988) birim kök testleri ile incelenmiştir. Ardından değişkenler arasında uzun dönemli ilişki olup olmadığını belirlemek amacıyla (Banerjee vd. 2017) tarafından geliştirilen Fourier ADL eşbütünleşme testi uygulanmıştır. Son olarak eşbütünleşik değişkenlerin uzun dönem parametre katsayıları belirlemek amacıyla dinamik en küçük kareler (DOLS) yöntemi kullanılmıştır.

\section{Augmented Dickey-Fuller (ADF) Birim Kök Testi}

Çalışmada serilerin durağanlığını ölçmek amacıyla Dickey-Fuller (1981) birim kök testi kullanılmıştır. $\mathrm{Bu}$ test birinci dereceden bir otoregresif sürecini kullanmaktadır. Dickey-Fuller (1981) gecikme uzunluğu p olarak belirlenmiş ve $\operatorname{AR}(\mathrm{p})$ modelinin sıfır hipotezinde $\operatorname{ARIMA}(\mathrm{p}, 1,0)$ otoregresif eşbütünleşik hareketli ortalama sürecini test etmektedir. 


$$
\begin{aligned}
& \Delta y_{t}=\gamma y_{t-1}+\sum_{i=2}^{p} \beta_{i} \Delta y_{t-i+1}+\varepsilon_{t} \\
& \Delta y_{t}=c+\gamma y_{t-1}+\sum_{i=2}^{p} \beta_{i} \Delta y_{t-i+1}+\varepsilon_{t} \\
& \Delta y_{t}=c+\gamma y_{t-1}+\delta_{2} t+\sum_{i=2}^{p} \beta_{i} \Delta y_{t-i+1}+\varepsilon_{t}
\end{aligned}
$$

Yukarda belirtilen üç regresyon modelinden birincisi (1) sabit terimsiz ve trend değişkeninin olmadığ1 modeldir. İkincisi (2) ilk modele göre sabit terimin dahil edildiği modeldir. Son model ise (3) hem sabit terim hemde trend değisşeninin dahil edildiği modeli göstermektedir. Burada bağımlı değişkenin bir dönem gecikmeli değerinin yt-1 katsayısı olan $\gamma$ birden küçük olup olmadığını test edilmektedir. Alternatif hipotez ise serinin durağan olduğu sonucuna ulaştırrr.

\section{Phillips ve Perron (1988) Birim Kök Testi}

Dickey-Fuller birim kök testinde sabit varyans ve hata terimlerinin bağımsız olduğu kabul edilmektedir. Dolayısıyla hata terimleri arasında otokorelasyon olmadığ1 varsayımı ortaya çıkmaktadır. Phillips ve Perron (1988), Dickey-Fuller (1979) tarafından geliştirilen varsayımları farklılaştırmış ve meydana gelecek rassal şoklar ile ilgili yeni varsayımda bulunmuşladır (Sevüktekin ve Nargeleçekenler, 2010, s. 365-366).

$$
Z_{t}=\left(\sum_{t=2}^{T} y_{t-1}^{2}\right)^{1 / 2} \frac{\hat{\alpha}-1}{s_{T l}}-(1 / 2) \frac{s_{T l}^{2}-s_{\varepsilon}^{2}}{\left[s_{T l}^{2}\left(T^{-2} \sum_{t=2}^{T} y_{t-1}^{2}\right)^{1 / 2}\right]}
$$

Phillips-Perron testi için gecikme parametresi $(l)$ otokorelasyon fonksiyonu hesaplanarak elde edilmektedir. Hesaplanan otokorelasyon katsayısına denk gelen nihai gecikme değeri dikkate alınmaktadır. Phillips-Perron testinde sıfır hipotez "birim kök vardır" şeklindedir ve hipotezler H0 : $\alpha=0$ ve H1 $: \alpha<0$ olarak kurulmaktadır. Test istatistiğinin asimptotik dağılımı ADF testi ile aynı olmasından dolayı test istatistiği MacKinnon kritik değerleri ile karşılaştırılır (Çağlayan ve Saçaklı, 2006, s.124).

\section{Fourier ADL Eşbütünleşme Testi}

Eşbütünleşme kavramı Engle-Granger (1987) ve Johansen (1988) tarfından yapılan çalışmalar ile literatüre kazandırılmıştır. İlerleyen dönemlerde zaman serilerine sahip değişkenler incelendiğinde meydana gelebilecek yapısal kırılma olasılığını tespit edilmiştir. Serilerin uzunluğu artıkça yapısal kırılma olasılığı da doğru orantılı olarak artmaktadır. Bu bağlamda adı geçen analiz yöntemler eleştiri almış ve sonuçların güvenirliliği tartışması ortaya çıkmıştır (Gazel, 2018, s. 534). Banerjee vd. (2017) tarafindan geliştirilen Fourier ADL testi Otoregresif gecikmesi dağıtılmış (ADL) denklemine Fourier fonksiyonlarının ilave edilmesiyle birden fazla bilinmeyen sayıda meydana gelebilecek yapısal kırlmayı yakalayarak uzun dönem eşbütünleşmeyi tahmin etmektedir (Banerjee vd., 2017).

5 numaralı denklemde Fourier Adl temel modeli gösterilmektedir.

$$
\Delta y_{1 t}=d(t)+\delta_{1} y_{1, t-1}+\gamma^{\prime} y_{2, t-1}+\varphi^{\prime} \Delta y_{2 t}+\varepsilon_{t}
$$


Burada $\gamma, \varphi_{\text {ve }}{ }^{y_{2 t}}$ nx1 parametrelerin vektörlerini ve bağımsız değişkenleri ifade etmektedir.

5 numaralı denklemde deterministik terimi $\mathrm{d}(\mathrm{t})$ aşağıdaki gibi tanımlanmaktadır.

$d(t)=\gamma_{0}+\sum_{k=1}^{q} \gamma_{1, k} \sin \left(\frac{2 \pi k t}{T}\right)+\sum_{k=1}^{q} \gamma_{2, k} \cos \left(\frac{2 \pi k t}{T}\right), q \leq T / 2$

Burada $\gamma_{0}$ sabit ve doğrusal bir eğilim içeren olağan deterministik terimi, $\mathrm{k}$ belirli bir tek frekansı temsil eder, q yaklaşımda bulunan frekansların sayısını temsil eder ve T, gözlemlerin sayısıdır. Uygun gecikme sayısının belirlenmesinde Akaike Bilgi Kriteri (AIC) kullanılmaktadır.

Fourier ADL testinin sıfır hipotezi değişkenler arasında eşbütünleşme olmadığını alternatif hipotez ise eşbütünleşme bulunduğunu ifade etmektedir.

$$
\begin{aligned}
& \mathrm{H}_{0}: \delta_{1}=0 \\
& \mathrm{H}_{1}: \delta_{1}<0
\end{aligned}
$$

Modelde sıfır hipotezini sınamada t-istatistiği kullanılmaktadır. Aynı zamanda H0: $\delta_{1}=\gamma=0$ eşitliğinde $\mathrm{F}$ testi uygulamak mümkündür. Hesaplanan test istatistiği belirlenen kritik değerlerin mutlak değerlerinden büyük olması durumunda $\mathrm{H} 0$ hipotezi reddedilerek değişkenler arasında eşbütünleşme olduğu kabul edilmektedir. Eğer test istatistiği belirlenen kritik değerlerin mutlak değerlerinden küçük ise değişkenler arasında bir eşbütünleşme olmadığı kabul edilmektedir (Banerjee vd. 2017, s. 118).

\section{Dinamik En Küçük Kareler (DOLS)}

Saikkonen (1991) ve Stock-Watson (1993) tarafindan geliştirilen yöntemde asimptotik olarak etkin tahminci elde edilmektedir. DOLS, eşbütünleşme sistemindeki geri-besleme durumunu eleyen DOLS hata terimi ile I(1) değişkenleri arasındaki korelasyondan kaynaklanan küçük örneklem yanllığının giderilmesi için birinci farkı alınan değişkenleri içerir (Caporale ve Chui, 1999).

DOLS denklemi aşağıdaki gibi ifade edilebilir:

$Y_{t}=X_{t}^{\prime} \beta+D_{t}^{\prime} \gamma_{1}+\sum_{j=-q}^{r} \Delta X_{t+j}^{\prime} \delta+v_{1 t}$

DOLS metodu, açıklayıcı değișkenlerin birinci farkını dikkate alır ve tahmine gecikmelerin dâhil edilmesine olanak tanır. Küçük örneklemlerde başarılı sonuçlara ulaşılabilmektedir (Erdoğan, Ceylan ve Tiryaki, 2018)

\section{Veri Seti}

Çalışmada kullanılan veriler 1985-2018 dönemini kapsayan ve yıllık olarak 34 gözlemden oluşmaktadır.

Tablo 4. Veri Seti

\begin{tabular}{clll}
\hline Kısaltma & Tanım & Dönem & Kaynak \\
\hline LGSYH & Gayri Safi Yurtiçi Hasıla & $1985-2018$ & Dünya Bankası \\
\hline LHDS & Hayat dişı sigorta Primleri & $1985-2018$ & OECD \\
\hline
\end{tabular}

Çalışmada gayri safi yurtiçi hasıla ve hayat dışı sigorta primleri serisi cari fiyatlar ile alınmıştır. Serileri zaman kısıtlamasının belirleyicisi ise veriye ulaşılabilirliktir. Tüm değişkenlerin logaritması alınmıştır.

\section{Bulgular}

Zaman serisi analizlerinde modellerde kullanılan değişkenler arasında ilişkiyi doğru bir biçimde ölçebilmek için serilerin durağan olması gerekmektedir. Çalışmada serilerin durağanlık analizleri, başka bir 
ifade ile serilerin birim kök içerip içermediğini Genişletilmiş Dickey-Fuller (ADF) ve Philips-Perron (PP) testleri kullanılmıştır.

Tablo 5. ADF Birim Kök Testi Sonuclar

\begin{tabular}{cccccc}
\hline \multirow{2}{*}{ Değişkenler } & \multicolumn{3}{c}{ Düzey Değeri I(0) } & \multicolumn{2}{c}{ Birinci Fark I(1) } \\
\cline { 2 - 6 } & Sabitsiz & Sabitli & Sabit+Trend & Sabitsiz & Sabitli \\
\hline LGSYH & 2.8992 & -1.3746 & -2.1932 & $-4.9778^{* * *}$ & $-6.1620^{* * *}$ \\
\hline LHDS & 3.1150 & -1.8087 & -1.3816 & $-4.2256^{* * *}$ & $-5.6041^{* * *}$
\end{tabular}

Not: *,** ve *** ifadeleri $\% 10, \% 5$ ve $\% 1$ seviyesinde anlamlılık düzeyini göstermektedir. Gecikme sayıları Schwarz bilgi kriterine göre belirlenmiştir.

ADF test sonuçları Tablo 5’te gösterilmiştir. Bu sonuçlara göre değişkenlerin tamamının düzey değerinde $\mathrm{I}(0)$ durağan olmadığını, birinci farkı alındığında $\mathrm{I}(1)$ durağan hale geldiği tespit edilmiştir. $\mathrm{Bu}$ durum serilerin birinci dereceden bütünleşik olduğunu göstermektedir.

Tablo 6. Philips-Perron (PP) Birim Kök Testi Sonuclarn

\begin{tabular}{|c|c|c|c|c|c|c|}
\hline \multirow{2}{*}{ Değişkenler } & \multicolumn{3}{|c|}{ Düzey Değeri } & \multicolumn{3}{|c|}{ Birinci Fark } \\
\hline & Sabitsiz & Sabitli & Sabit+Trend & Sabitsiz & Sabitli & Sabit+Trend \\
\hline LGSYH & 2.8992 & -1.3746 & -2.2204 & $-5.0721^{* * *}$ & $-6.1620^{* * *}$ & $-6.2513^{* * *}$ \\
\hline LHDS & 3.2049 & -1.9841 & -1.3525 & $-4.3996^{* * *}$ & $-5.6043^{* * *}$ & $-6.2156^{* * *}$ \\
\hline
\end{tabular}

Not: *,** ve *** ifadeleri $\% 10, \% 5$ ve $\% 1$ seviyesinde anlamlılık düzeyini göstermektedir. Gecikme sayıları Schwarz bilgi kriterine göre belirlenmiştir.

PP test sonuçları Tablo 6'te gösterilmiştir. Bu bağlamda sonuçlara göre değişkenlerin tamamının düzey değerinde $\mathrm{I}(0)$ durağan olmadığını, birinci fark1 I(1) alındığında durağan hale geldiği tespit edilmiştir. $\mathrm{Bu}$ durum $\mathrm{ADF}$ test sonuçlarına benzer şekilde serilerin birinci dereceden bütünleşik olduğunu göstermektedir.

Tablo 7. Fourier ADL Eşbütünleşme Testi Sonuçlarn

\begin{tabular}{cccccc}
\hline & Bağımlı D. & Bağımsı D. & Frekans & Min AIC & Test İstatistiği \\
\hline Model & LGSYH L(3) & LHDS L(1) & 1 & -2.1760 & -4.3264
\end{tabular}

Not: Fourier ADL eşbütünleşme testi için bağımsız değişken sayısı n=1, frekans=1 ve gözlem sayısı=34'tür. Dolayısıyla

kritik değerler \%1, \%5 ve \%10 anlamlılık düzeylerinde sırasıly $-5.17,-4.55$ ve -4.24 şeklindedir (Banerjee vd. 2017, s. 118).

Tablo 7'de Fourier ADL eşbütünleşme test sonuçları görülmektedir. Burada LO ile ifade edilen değerler değişkenlerin gecikme sayılarını göstermektedir. Bu sonuçlara göre eşbütünleşme test istatistiği \%10 seviyesinde kritik değerden yüksek bulunmuştur. Dolayısıyla değişkenler arasında eşbütünleşme yoktur olarak ifade edilen sıfır hipotezi reddedilerek değişkenler arasında uzun dönemli bir eşbütünleşme tespit edilmiştir.

Çalışmanın bu kısmında Fourier ADL test sonuçlarına göre uzun dönem eşbütünleşme tespit edilen modelin parametre tahminlerini yapmak amaciyla Dinamik En Küçük Kareler Yöntemi (DOLS) kullanılmıştır.

Tablo 8. Dinamike En Küçük Kareler (DOLS) Sonuclar

\begin{tabular}{|c|c|c|c|c|}
\hline Bağımlı Değişken & LGSYH & & & \\
\hline Bağımsız Değişkenler & $\beta$ & Std. Hata & T-İstatistiği & Olasılık Değeri \\
\hline LHDS & 0.7191 & 0.0332 & 21.6092 & 0.0000 \\
\hline $\mathrm{C}$ & 20.8080 & 0.2917 & 71.3288 & 0.0000 \\
\hline \multicolumn{5}{|c|}{ Modele İlişkin İstatistikler } \\
\hline $\mathrm{R}^{2}$ & 0.9870 & & M. Dep. Var & 26.4195 \\
\hline Adj. $\mathrm{R}^{2}$ & 0.0943 & & S.D. Dep. Var & 0.8106 \\
\hline S.E. of Reg & 0.1013 & & Sum Squared Res. & 0.2463 \\
\hline Long Run Var. & 0.0279 & & & \\
\hline
\end{tabular}

Not: Uygun gecikme sayılarının belirlenmesinde Schwarz bilgi kriteri kullanılmış ve maksimum gecikme uzunluğu 2 olarak belirlenmiştir.

Tablo 8'da belirtilen DOLS sonuçlarına göre, LHDS değişkenin beklentiler doğrultusunda katsayısının pozitif ve $\% 1$ düzeyinde istatistiksel olarak anlamlı olduğu görülmektedir. Bu sonuca göre 
hayat dışı sigorta primlerinde meydana gelecek $\% 1^{\prime}$ lik bir artış ekonomik büyümede yaklaşık $\% 0,71^{\prime}$ lik bir artışa neden olmaktadır.

Analiz bulguları sigortacllıkla ekonomik büyüme arasında uzun dönemli bir eşbütünleşme ilişkisini ortaya koymaktadır. Literatürde benzer çalışmalar incelendiğinde sigortacılık ve ekonomik büyüme arasında olumlu yönde anlamlı ilişki bulunduğu sonucuna ulaşıldığı gözlemlenmiştir. Şenol, 2020 ve Şamiloğlu, 2019 gibi güncel çalışmaların sonuçlan da olumlu ilişkiyi desteklemektedir.

\section{Sonuç ve Öneriler}

Sigortacıllğın temel amacı riskli dönemlerde kayıpları azaltarak veya telafi ederek toplumsal refahı artırmaktır. Bunun yanında sigortacıllk sektörü makroekonomik anlamda önemli bir pozitif dışsallık oluşturmaktadır. Sektörde risk karşıllı̆ıında toplanan fonlar tasarruflara dönüşerek hem reel hem de finansal anlamda önemli bir yatırım kaynağı haline gelmiştir. Bu durum ise sigortacılık sektörünü her geçen gün talebi artan bir pazar haline getirmiştir.

1985-2018 döneminde Türkiye'de hayat dışı sigortacılık ve ekonomik büyüme ilişkisini ölçmeyi amaçlayan bu çalışmada, bağımlı değişken olarak gayrisafi yurtiçi hasıla ve bağımsız değişken olarak hayat dışı sigortacılık primleri belirlenmiştir. Çalışmada öncelikle değişkenlerin durağanlıkları test edilmiştir. Elde edilen test sonuçlarına göre her iki değişenin birinci farklarında durağan hale geldikleri tespit edilmiştir. Ardından değisskenler arasında uzun dönemli ilişki olup olmadığını tespit edebilmek amacıyla yapısal kırılmaları yakalayan Fourier ADL eşbütünleşme testi uygulanmıştır. Bu test sonucuna göre değişkenleri uzun dönemde eşbütünleşik olduğu tespit edilmiştir. Son olarak uzun dönem parametre katsayıları tahmini için DOLS yöntemi kullanılmıştır. Sonuç olarak hayat dışı sigortacilığın ekonomik büyümeyi pozitif yönde etkilediği tespit edilmiştir.

Çalışma sonuçları literatürdeki benzer çalışmalar ile karşılaşıırıldığında, yapılan analizlerin büyük bir bölümünde sigortacılık ile ekonomik büyüme arasında olumlu yönde bir ilişki bulunduğu gözlemlenmiştir. Ancak uzun vadede bu olumlu ilişkinin korunabilmesi ve sürdürülebilir olması için sigorta sektörüne yapılan yatırımların ve desteklerin artırılmasının önemi vurgulanmıştır. Sigorta sektörüne yapılan yatırımların istihdamı artırarak ve kayıpları telafi ederek toplumsal refahı arttırabileceği belirtilmiştir. Sigorta sektörünün düşük penetrasyon oranı büyüme potansiyeline işaret ederken, bu oranın arttırılmasına yönelik stratejiler belirlenmesi yerleşmiş sorunların çözümünde yol haritası olması bakımından önem taşıyabilmektedir.

Çalışmada elde edilen sonuçlara göre Türkiye'de beklentiler doğrultusunda sigortacılık sektörünün ekonomik büyümeye pozitif katkısı olduğu tespit edilmiştir. Bu bağlamda katkı seviyesini artırmak amaciyla politika belirleyicilerin sigortacılık sektöründe teşvik artırıcı birtakım programlar uygulanması önerilmektedir. Bunlardan bazıları, özellikle yerli şirketlere büyümeleri adına çeşitli sübvansiyonlar sağlanması, halkı sigorta anlaşması için teşvik edecek çeşitli kanun ve uygulamaların ortaya konulmasıdır (vergi oranlarının düşürülmesi vb.). Sigortaya karşı geleneksel bakış açısının değiştirilmesi ve sigorta ürünlerine olan güvenin artırılarak toplumsal sigorta bilincinin sağlanması sigortalılık oranlarının artması açısından önem taşımaktadır. Bu kapsamda acentelere ve sigorta sektörü çalışanlarına sağlanacak eğitimler ile müşteri ilişkilerinin geliştirilmesi ve ürünlerin doğru şekilde pazarlanması ve sigorta farkındalığının oluşturulması önerilmektedir. Sigortacılık alanında uzmanlaşmış ve teknik bilgi düzeyi yüksek yöneticilerin varlığ1 sektöre duyulan güvenin arttırlması bakımından faydalı olabilecektir.

Katastrofik risklerin ve doğurduğu kayıpların giderek arttı̆̆ bir dönemde hayat dışı sigorta ürünlerinin ekonomik kayıpları azaltabileceğinden sigorta şirketlerinin bu risklerin yönetilmesi konusunda çalışmalar yapması teşvik edilmelidir. Deprem sigortasında olduğu gibi devletin, özel sektörün ve bilim insanlarının ortak çalışması ile riskler yönetilmeli ve olası kayıpları en aza indirecek çalışmalar yapılmalıdır. Özel sektör ve devlet arasında entegrasyon sağlanması ve sigortacilık reformlarının yapılması sektörün potansiyelini ortaya koyarak büyümeyi destekleyebilecektir. Hayat dişı sigorta ürünlerinde artan büyümeyle birlikte, devletin üzerinde sigortalanabilir risklerden doğan finansal yük azalabilecek ve sağlanan tasarruflar yatırıma yönlendirilerek ekonomik büyümeyi pozitif yönde ilerletmeye devam edebilecektir.

\section{Etik Beyan}

"Hayat Dışı Sigortacllke ve Ekonomike Büyüme İlişkisi: 1985-2018 Türkiye Örneğg” başlıklı çalışmanın yazım sürecinde bilimsel kurallara, etik ve alıntı kurallarına uyulmuş; toplanan veriler üzerinde herhangi bir tahrifat yapılmamış ve bu çalışma herhangi başka bir akademik yayın ortamına değerlendirme için 
gönderilmemiştir. Bu araştırmada hazır veri seti kullanıldı̆̆ı için etik kurul kararı zorunluluğu taşımamaktadır.

\section{Kaynakça}

Apergis N. ve Poufinas T. (2020). The role of insurance growth in economic growth: Fresh evidence from a panel of OECD countries. North American Journal of Economics and Finance, 53, 1-16. doi: https://doi.org/10.1016/j.najef.2020.101217

Banerjee, P., Arcabic, V. ve Lee, H. (2017). Fourier ADL cointegration test to approximate smooth breaks with new evidence from crude oil market. Economic Modelling, 67/C, 114-124. doi: https://doi.org/10.1016/j.econmod.2016.11.004

Caporale, G. ve M. Chui (1999). Estimating income and price elasticities of trade in a cointeglation framework. Review of International Economics. 7(2), 254-264.

Çağlayan, E. ve Saçaklı, İ. (2006). Satın alma gücü paritesinin geçerliliğinin sıfır frekansta spektrum tahmincisine dayanan birim kök testleri ile incelenmesi. Atatürk Üniversitesi İktisadi ve İdari Bilimler Dergisi, 20(1), 121-137.

Demirci Ş. D. ve Zerren F. (2017). Insurance premium and economic growth: evidence from OECD countries. İsletme Bilimi Dergisi (JOBS), 5(1), 1-11

Dickey, D. A. ve Fuller, W. A. (1981). Likelihood ratio statistics for autoregressive time series with a unit root. Econometrica, 49(4), 1057-1072.

Dickey, D. A. ve Fuller, W. A. (1979). Distribution of the estimators for autoregressive time seres with a unit root. Journal of the American Statistical Association, 74, 366, 427-431.

Engle, R. F. ve Granger, C. W. J. (1987). Co-integration and error correction: Representation, estimation and testing. Econometrica, 55(2), 251-276.

Gazel, S. (2018). Değerli metaller ve makroekonomik değişkenler: Türkiye için bir Fourier eşbütünleşme testi uygulamas1, yönetim ve ekonomi. Manisa Celal Bayar Üniversitesi İ.̇.B.F., 25(2), 527-542.

Haiss, P. ve Sümegi, K. (2008). The relationship between insurance and economic growth in Europe: A theoretical and empirical analysis. Empirica, 35, 405-431.

Harrod, R. F. (1939). An essay in dynamic theory. Economic Journal, 49, 14-33.

Johansen, S. (1988). Statistical analysis of cointegration vectors. Journal of Economic Dynamics and Control, 12(2-3), 231254.

Kaya, N. ve Kilıç, N. (2020). The effect of insurance premium on economic growth in European Union countries: Panel data analysis. Akademike Araștrmalar ve Cahısmalar Dergisi (Akad), 12(23), 442-451.

Köse, A., Akpınar Ö. ve Demirbilek İ. (2009). Türk sigorta sektöründe prim üretimi ile ekonomik büyüme arasındaki eşbütünleşme ilişkisi 1981-2008. TSEV Sigorta Araştırmalar Dergisi, s. 3-15.

Kugler, M. ve Ofoghi, R. (2005). Does Insurance Promote Economic Growth? Evidence from the UK. RePEc Search, $1-27$.

Liu, G. C., Lee, C. C. ve Lee, C.C. (2016). The nexus between insurance activity and economic growth: A bootstrap rolling window approach. International Review of Economics and Finance, 43, 299- 319.

Lucas, R. E. Jr. (1988). On the mechanics of economic development. Journal of Monetary Economics, 22(1), 3-42.

Phillips, P.C. B. ve Perron, P. (1988. Testing for a unit root in time series regression. Biometrika, 75(2), 335-346.

Pradhan, R. P., Arvin, B. M., Norman, N. R., Nair, M. ve Hall, C. H. (2016). Insurance penetration and economic growth nexus: Cross-country evidence from ASEAN. Research in International Business and Finance, 36, 447-458.

Romer, P. M. (1986). Increasing returns and long-run growth. Journal of Political Economy, 94(5), 1002-1037.

Saikkonen, P. (1991). Asymptotically efficient estimation of cointegration regressions. Econometric Theory, 7, 1-21.

Senol, Z., Zeren, F. ve Canakci, M. (2020). The relationship between insurance and economic growth. Montenegrin Journal of Economics, 16(4), 145-155. doi: 10.14254/1800-5845/2020.16-4.12

Sevüktekin, M. ve Nargeleçekenler, M. (2010). Ekonometrik zaman serileri analiæi: EViews uygulamalı. Ankara: Nobel Yayın Dağıtım.

Sigma. (2020). World insurance: Riding out the 2020 pandemic storm, No 4/2020.

Solow, R. (1956). A contribution to the theory of economic growth. Quarterly Journal of Economics, 70, 65-75.

Stock, J. H. ve Watson, M. W. (1993). A simple estimator of cointegrating vectors in higher order integrated systems. Econometrica, 61(4), 783-820.

Şamiloğlu, F., Eser, F. ve Bağc1, H. (2019). Türkiye'de sigortacıllk sektörünün makroekonomik değişkenlerle olan ilişkisi. Ekonomi ve Yönetim Araştırmalar Dergisi, 8(1), 24-40.

T.C. Hazine ve Maliye Bakanlığ1. (2018). Sigorta Denetleme Kurulu. Sigortacllk ve Bireysel Emeklilik Faaliyetleri Hakkinda Rapor.

$\begin{array}{lllll}\text { Türkiye } & \text { Sigorta } & \text { Birliği, } & \text { (2019), Rektör } & \text { Raporu. }\end{array}$ https://tsb.org.tr/Document/Yayinlar/TSB2019SEKThtml/index.html

Türkiye Sigorta Birliği, Sigorta Branşları, Erişim Adresi: https://www.tsb.org.tr/sigorta-branslari.aspx?pageID=622

Uralcan G. Ş. (2014). Sigorta sektöründe Rigor Mortis (Ölüm Katıllı̆̆) ve değişim faaliyetlerinin analizi. Finansal Araștırmalar ve Calismalar Dergisi, 3(5), 21-41. 
Uralcan, G. Ş. (2012). Sigorta faaliyetlerinin işlevsel açıdan değerlendirilmesi ve Türk sigorta sektörünün bu bağlamda dünya sigorta şirketleriyle karşılaştırılması. Sosyal ve Beşeri Bilimler Dergisi, 4(1), 125-134.

Vadlamannati, K. C. (2008). Do insurance sector growth and reforms affect economic development? Empirical evidence from India. The Journal of Applied Economic Research, 2(1), 43-86.

Ward, D. ve Zurbruegg, R. (2000). Does insurance promote economic growth? Evidence from OECD countries. The Journal of Risk and Insurance, 67(4), 489-506.

Yenisu E. (2019). Sigortacılık sektörü ve ekonomik büyüme ilişkisi: Türkiye örneği. Finans Ekonomi ve Sosyal Araştırmalar Dergisi, 4(2), 206-217.

\section{EXTENDED ABSTRACT}

Insurance has emerged from the need of people to secure themselves against the losses caused by these risks in a universe full of risks and it has become an important financial sector today. Insurance is not only a premium and indemnity relationship, but also a structure that has multifaceted economic and social functions. Insurance can reduce economic losses with an effective risk management and support investments with the funds accumulated in the pool. When insurance is evaluated according to its branches, it is examined in two groups as life insurances and non-life insurances. Non-life insurance branch includes; causality, fire, earthquake, marine, engineering, liability, agriculture, general damages and financial loss insurance. The widespread use of non-life insurance products and the increase in the number of insured persons alleviate the burden on the national economy by minimizing financial losses. Extreme damages caused by natural disasters such as earthquakes, floods and tsunamis can be overcome with a developed insurance system in a way that causes the least loss to the country's economy. For this reason, increasing the insurance rate of non-life products may increase the payment elasticity against economic losses.

One of the macroeconomic important functions of insurance is that it positively affects domestic savings. The premiums determined by the contracts are accumulated in the insurance pool, both reducing risks and creating an important source of savings. The transformation of domestic savings into investments, thus supporting economic growth, has been the subject of growth models in the literature. It is thought that the high level of insurance penetration in countries with a developed insurance system supports this situation.

It is believed that the Turkish insurance industry has a significant growth capacity. Turkey's young and dynamic structure and the strategic support of the state to the sector in products such as agriculture and TCIP may create various opportunities in terms of insurance. It also Turkey's economy has high growth potential and low penetration rates in the long term be able to support their growth forecasts for the insurance. Compared with developed countries, it is possible to tell whether the desired level of insurance in Turkey. In 2019, real growth rates for non-life insurance in Turkey was realized as 1.9\% in developed markets, this ratio was $0.5 \%$. Considering the amount of premiums per capita world average of 818 US Dollars, while in Turkey (111 US Dollars mainly in the non-life products) was US $\$ 131$. The share of direct premiums in GDP stood at 7.23 in the world, while 1.45 percentage points in Turkey.

In the analysis part of the study, the presence of unit root in variables was examined using Augmented Dickey-Fuller (ADF) and Phillips-Perron (1988) root tests. The Fourier ADL cointegration test was conducted by using whether there is a long-term relationship between the verified variables (Banerjee et al.2017). Finally, the dynamic least squares (DOLS) method was used to determine coherently variable long-type coefficients.

The data used in the study consists of 34 observations per year, covering the period 1985-2018. In the study, economic growth and non-life insurance premiums series are taken with current prices. The determinant of the time constraint of the series is the accessibility of the data. The logarithms of all variables are taken. In the study, gross domestic product and non-life insurance premiums series are taken with current prices. The determinant of the time constraint of the series is the accessibility of the data. The logarithms of all variables are taken.

This study aimed to measure the non-life insurance and economic growth relationship between 19852018 in Turkey. Gross domestic product is determined as dependent variable and non-life insurance premiums as independent variable. First of all, the stationaries of variables were tested in the study. According to the test results obtained, it was determined that both variables became stationary in their first differences. Afterwards, Fourier ADL cointegration test, which captures structural breaks, was applied to determine whether there is a long-term relationship between variables. According to the result 
of this test, it was determined that the variables are cointegrated in the long term. Finally, the DOLS method was used for the estimation of long-term parameter coefficients. As a result, it has been determined that non-life insurance has a positive effect on economic growth.

According to the results obtained in this study, in line with expectations of the insurance sector in Turkey it has been found to be a positive contributor to economic growth. In this context, it is recommended that policy makers implement some incentive-increasing programs in the insurance sector to increase the level of contribution. Some of these include providing various subsidies to domestic companies for their growth, introducing various laws and practices (lowering tax rates, etc.) to encourage the public for insurance agreements. Changing the traditional perspective on insurance and raising the awareness of social insurance by increasing the trust in insurance products are important for increasing the number of insured individuals. In this direction, In this direction, it is recommended to develop customer relations with trainings to be provided to agencies and insurance sector employees and to create insurance awareness by marketing the products correctly.

In a period in which catastrophic risks and the losses they cause are increasing, insurance companies should be encouraged to work on the management of these risks, as non-life insurance products may reduce economic losses. As in earthquake insurance, the risks should be managed with the cooperation of the government, the private sector and scientists, and studies should be done to minimize possible losses. Integration between the private sector and the state, and insurance reforms will be able to support growth by revealing the sector's potential. With the increasing growth in non-life insurance products, the financial burden on the state arising from insurable risks may decrease and the savings achieved will be directed to investment and the economic growth will be able to continue to advance positively. 